\title{
Air pollution and children's respiratory health
}

\author{
Chris Carlsten MD MPH ABIM FRCPC
}

$\mathrm{T}$ he impact of air pollution on children's lungs is significant, but it is important to develop country-specific data to inform and impact local policies. Accordingly, in the current issue of the Journal, Rodriguez-Villamizar et al (1) (pages 282-292) reviewed 27 articles from four provinces in Canada to distill the Canadian literature regarding this topic and provide insight. This is a great service to those who inevitably yearn for the diverse Canadian evidence to be crystallized into a 'digestible' format. In spite of the heterogeneity, they describe adverse effects similar to those found elsewhere in the world, providing support for those who believe that pollution-control efforts here should be just as aggressive as in Europe or the United States, even if Canadian air pollution exceedances have not typically been as dramatic as those elsewhere.

Rodriguez-Villamizar et al (1) are to be commended for thus having conducted a systematic review of the literature for the effects of outdoor air pollution on children's respiratory health in Canada. They reviewed the information in four electronic databases from January 2004 up to November 2014 to identify 27 epidemiological studies evaluating the effect of exposure to outdoor air pollutants on respiratory end points in Canadian children. The selection process and quality assessment using the Newcastle-Ottawa Scale (NOS) was conducted independently by two reviewers.

The review is somewhat limited by its heavy reliance on data from Ontario relative to the rest of Canada and, more importantly, there is little ability to argue whether the results are specific to Canadian children. Furthermore, the authors recognize that the NOS for assessing the quality of nonrandomized studies in meta-analyses is not ideally suited to the context of this particular analysis, and yet do not offer a better option (several better such tools exist [2], although RodriguezVillamizar et al [1] argue for developing and validating yet another tool). Accordingly, the quality suffers somewhat under the AMSTAR evaluation (3).

Nevertheless, it is notable that some studies in this review reported adverse effects of outdoor air pollution at concentrations that were below Canadian and United States standards. Most importantly, perhaps is the authors' recommendation for future work. Appropriately, they advise that methodological gaps be addressed and that heterogeneity be more deeply probed.

Our own work (4) (not included in the Rodriguez-Villamizar study) embraces the call to 'fill gaps', bears out the concerns for children as a susceptible population and adds considerably to them given that an air pollution-attributable increase in asthma incidence (little is addressed in the review) was found with particular susceptibility conferred by common genetic variants. This, in part, addresses the 'why' that Rodriguez-Villamizar et al (1) rightly implore we better understand. Other heterogeneity (related to sex and socioeconomic status, for example) suggests ongoing need for evaluation of susceptibility factors. We found that children at particularly high risk for asthma, by virtue of family history, developed asthma in response to traffic-related pollution that was only modestly elevated according to international standards (5). Collectively, this evidence is pushing us to carefully consider how to leverage emerging data regarding susceptibility factors in a cost-effective way using a public health lens (6).

Overall, the review by Rodriguez-Villamizar (1) reminds us that while air quality improves in much of the world, and while Canada enjoys excellent air quality in general, advanced research methods are now able to detect subtle signals of adverse health effects better than ever before, such that we see potential benefit in further air quality gains. The heterogeneity in the studies reviewed by RodriguezVillamizar (1) provides indirect support to those who argue that improved understanding of susceptibility will help target remaining areas for most impact.

\section{REFERENCES}

1. Rodriguez-Villamizar LA, Magico A, Osornio-Vargas A, Rowe BH. The effects of outdoor air pollution on the respiratory health of Canadian children: A systematic review of epidemiological studies. Can Respir J 2015;22:282-92.

2. Sanderson S, Tatt ID, Higgins JP. Tools for assessing quality and susceptibility to bias in observational studies in epidemiology: A systematic review and annotated bibliography. Int J Epidemiol 2007;36:666-76

3. Shea BJ, Grimshaw JM, Wells GA, et al. Development of AMSTAR: A measurement tool to assess the methodological quality of systematic reviews. BMC Med Res Methodol 2007;7:10.

4. MacIntyre EA, Brauer M, Melén E, et al. GSTP1 and TNF gene variants and associations between air pollution and incident childhood asthma: The traffic, asthma and genetics (TAG) study. Environ Health Perspect 2014;122:418-24.

5. Carlsten C, Dybuncio A, Becker A, Chan-Yeung M, Brauer M. Traffic-related air pollution and incident asthma in a high-risk birth cohort. Occup Environ Med 2011;68:291-5.

6. Carlsten C, Brauer M, Brinkman F. Genes, the environment and personalized medicine: We need to harness both environmental and genetic data to maximize personal and population health. EMBO Rep 2014;15:736-9.

\footnotetext{
Respiratory Division, Department of Medicine, University of British Columbia, Vancouver, British Columbia

Correspondence: Dr Chris Carlsten, Respiratory Division, Department of Medicine, University of British Columbia, 2775 Laurel Street, 7 th Floor,

Vancouver, British Columbia V5Z 1M9. Telephone 604-875-4729, fax 604-875-4727, e-mail carlsten@mail.ubc.ca
} 


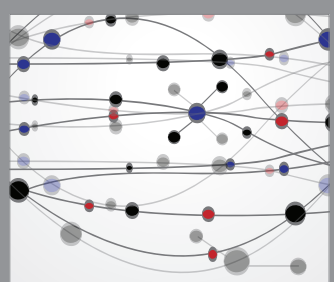

The Scientific World Journal
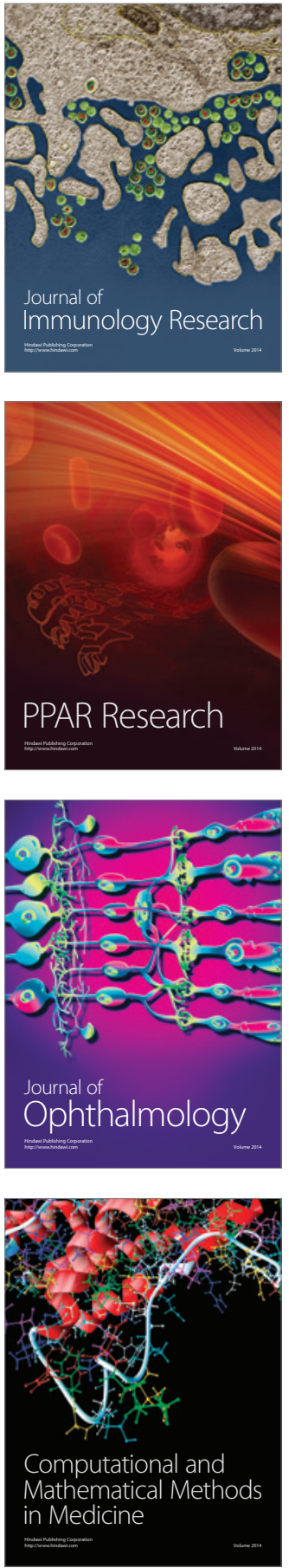

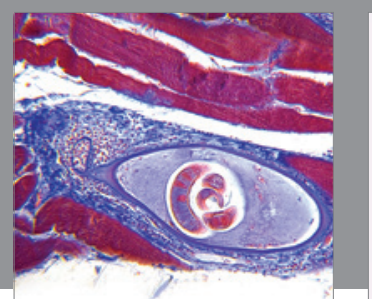

Gastroenterology Research and Practice

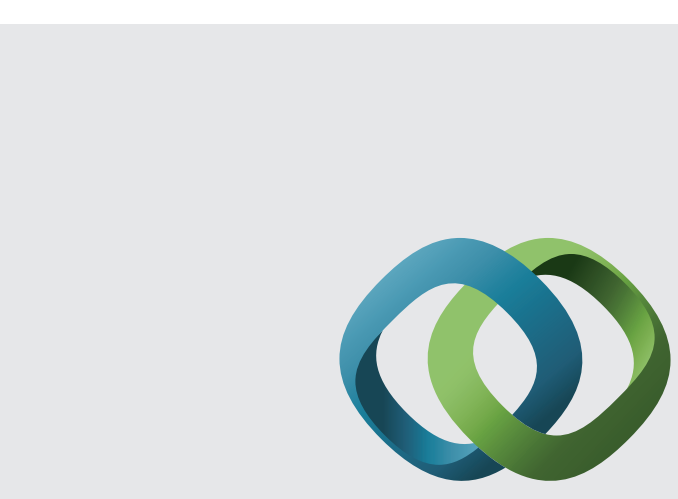

\section{Hindawi}

Submit your manuscripts at

http://www.hindawi.com
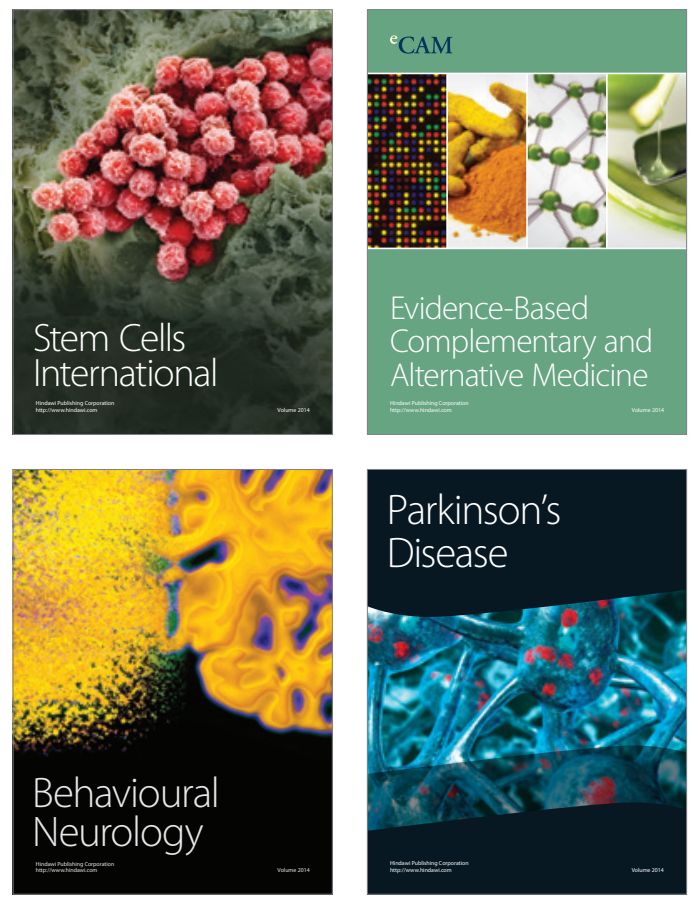
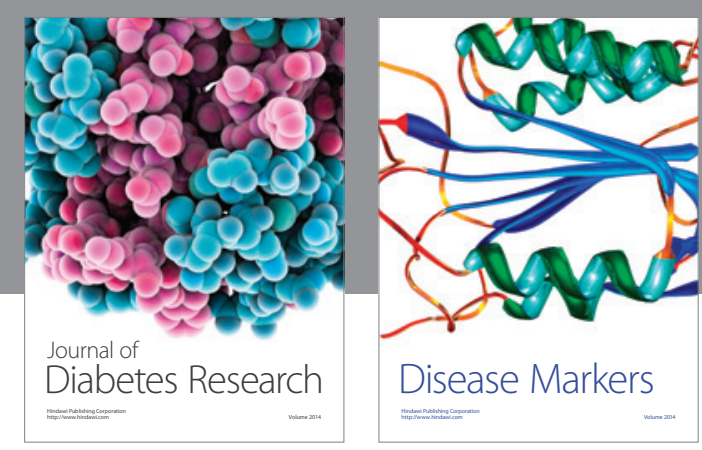

Disease Markers
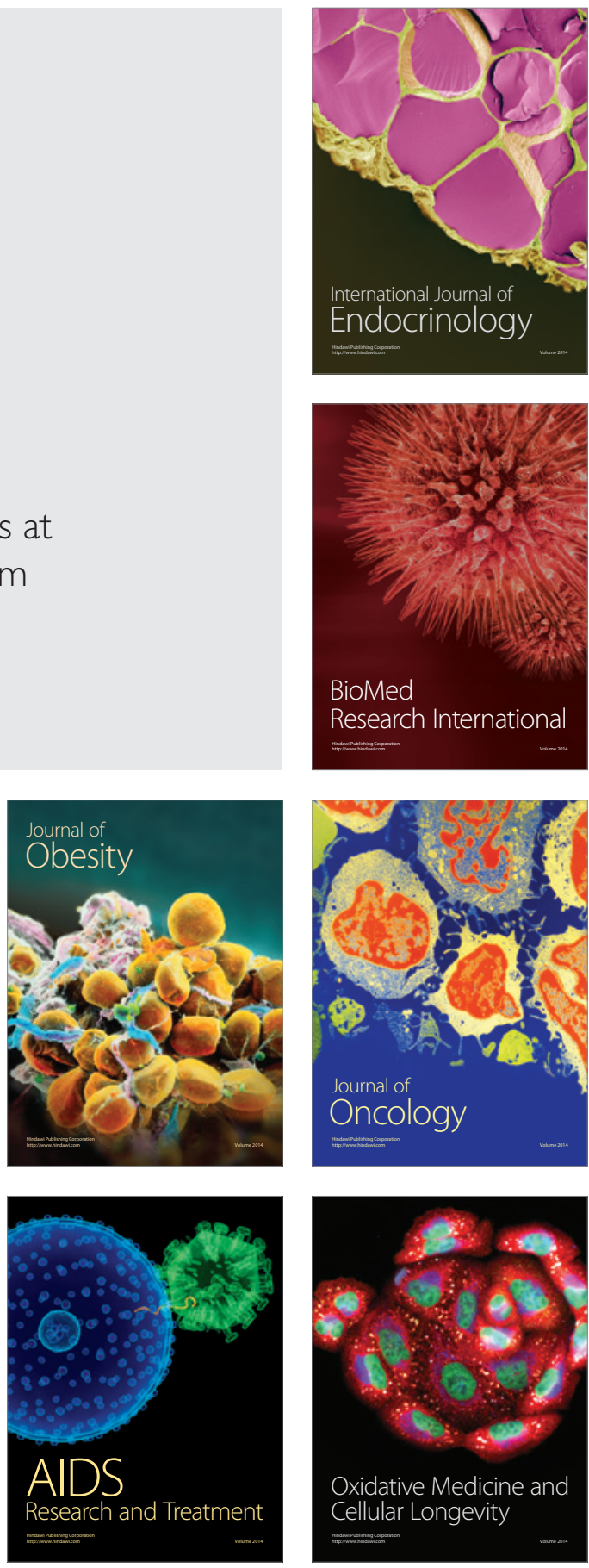